Article

\title{
The Effect of Building Aspect Ratio on Energy Efficiency: A Case Study for Multi-Unit Residential Buildings in Canada
}

\author{
Philip McKeen ${ }^{1, *}$ and Alan S. Fung ${ }^{2}$ \\ 1 Department of Architectural Science, 325 Church Street, Toronto, ON M5B 2K3, Canada \\ 2 Department of Mechanical and Industrial Engineering, 350 Victoria Street, Toronto, ON M5B 2K3, \\ Canada; E-Mail: alanfung@ryerson.ca
}

* Author to whom correspondence should be addressed; E-Mail: pmckeen@ryerson.ca; Tel.: +1-604-559-7979.

Received: 17 April 2014; in revised form: 24 June 2014 / Accepted: 25 June 2014 /

Published: 9 July 2014

\begin{abstract}
This paper examines the energy consumption of varying aspect ratio in multi-unit residential buildings in Canadian cities. The aspect ratio of a building is one of the most important determinants of energy efficiency. It defines the building surface area by which heat is transferred between the interior and exterior environment. It also defines the amount of building area that is subject to solar gain. The extent to which this can be beneficial or detrimental depends on the aspect ratio and climate. This paper evaluates the relationship between the geometry of buildings and location to identify a design vernacular for energy-efficient designs across Canada.
\end{abstract}

Keywords: aspect ratio; energy efficiency; geometry

\section{Introduction}

The building envelope has the task of protecting the interior environment from less desirable exterior conditions. The extent to which it fulfills this role affects the energy consumption through heating and cooling. A well-designed building envelope will require less energy, create less combustion products and reduce operating cost. The design process is driven by a number of factors, with the goal of providing a functional, cost-effective living environment. It governs all attributes, such as the geometry, orientation, materials and construction methods. "Choosing a good building shape and orientation are two of the most critical elements of an integrated design" (as cited Chiras [1]). The 
building footprint must be decided upon early in the planning stages and has a profound impact on energy consumption. Thus, selecting the optimal building geometry is a critical early step in the design of sustainable buildings.

Multi-unit residential buildings (MURBs) represent a significant proportion of the housing sector in cities. Within Toronto, statistics indicate that $56 \%$ of dwellings are MURBs. Of these, $39 \%$ are mid-rise or high-rise MURBs [2]. In Ontario, MURBs account for an annual energy use of over 58 million gigajoules [3]. This is just over $10 \%$ of the total energy consumed by all residential buildings in Ontario and indicates that MURBs, by their population density, are more energy efficient than single-family detached homes (Figure 1). However, because of the density of mid- and high-rise MURBs, addressing energy efficiency is more practical and cost effective than for smaller buildings.

Figure 1. Total annual energy consumption of households in Ontario and BC (Million GJ) [3].

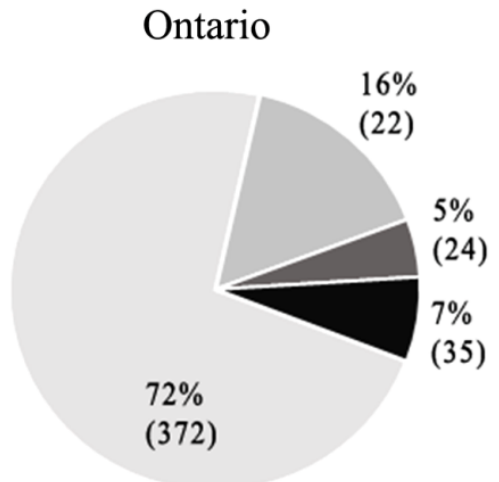

Detached House $\square$ Double/row house
British Columbia

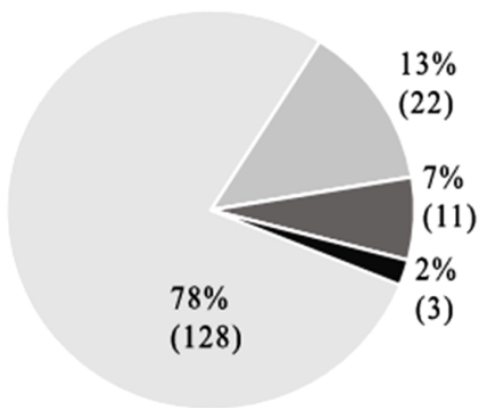

Low-Rise $\mathbf{a}$ High-Rise

\subsection{The Internal Environment}

Achieving occupant comfort is a priority that has a great effect on energy demand, particularly in cold climate zones. Maintaining a proper interior environment involves contrasting heat gain and loss. This gain and loss can vary broadly among building types. For instance, buildings with a high electrical load, such as data centers, will have a high heat gain and an emphasized strategy for the removal of heat. However, residential buildings tend to have less internal heat gains, and the enclosure is more important in maintaining the internal environment temperature efficiently [4].

The energy use in buildings is derived considerably from heating, cooling, lighting and appliance loads. Additionally, the electrical loads in suites that effect the heating and cooling demands can be quite significant. The energy consumption in one study of MURBs in BC found that lighting and appliances consume $20 \%$ of the energy in buildings with electrically heated baseboards. Over $45 \%$ of the energy use was from heating [5]. However, the proportional energy use varies greatly, depending on the location and building parameters.

\subsection{The Envelope: Thermal Transfer and Area}

The envelope's efficiency is often discussed in terms of its thermal properties in heat transfer by the process of conduction, convection and radiation. The transfer of thermal energy occurs at the exterior 
surface of the building. The total surface area subject to thermal transfer is a function of its dimensions or aspect ratio. The aspect ratio quantifies the building's footprint in a ratio of length and width (x:y) and allows for the comparison of the surface area amongst different building designs. The change in aspect ratio can be described to increase relative to the east-west or north-south axis for orthogonal building arrangements. An increase in the aspect ratio can vary the amount of building envelope subject to solar radiation (Figure 2).

Figure 2. The increase of building dimensions $(x, y)$ will change the aspect ratio along a particular axis.

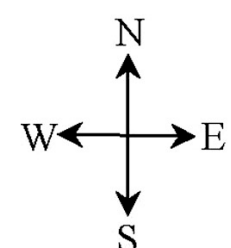

Aspect Ratio:

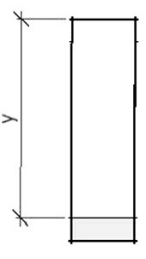

$y$

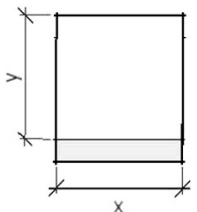

$1: 1$

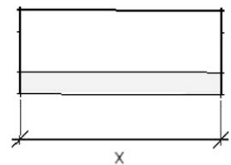

$x: 1$

Increasing Aspect Ratio along North-South Axis

Increasing Aspect Ratio along East-West Axis

The building's aspect ratio determines the amount of surface area from which heat will be transferred to and from the environment. Minimizing the amount of surface area reduces energy transfer [6]. An analysis of geometry reveals that changing the aspect ratio results in different surface areas for an equivalent floor area (Figures 3 and 4). Designs that require more surface area will thus have a greater quantity of heat transfer. The effect of the aspect ratio on the exterior surface area will have a larger impact on smaller building footprints (Figure 5). The minimum surface area is achieved with a 1:1 aspect ratio. However, in the presence of solar radiation, the ideal aspect ratio becomes a balance of heat loss and gain.

Figure 3. Geometrical relationship between surface area and the aspect ratio.

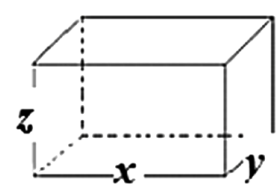

Aspect Ratio X:Y

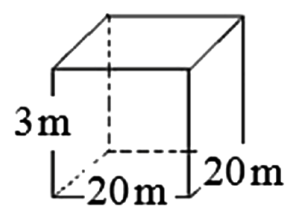

Aspect Ratio 1:1

$\begin{array}{rcc}\begin{array}{r}\text { Wall Surface } \\ \text { Area }\end{array} & 2 x z+2 y z & 240 \mathrm{~m}^{2} \\ \text { Floor Area } & x y & 400 \mathrm{~m}^{2} \\ \begin{array}{r}\text { Wall Surface } \\ \text { to Floor Area } \\ \text { Ratio }\end{array} & \frac{2 z}{y}+\frac{2 z}{x} & 0.6 \text { or } 60 \%\end{array}$

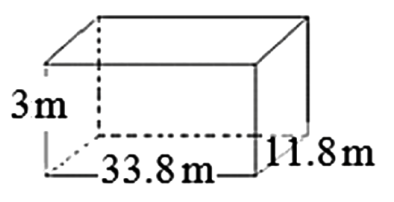

Aspect Ratio 3:1

$274 \mathrm{~m}^{2}$

$400 \mathrm{~m}^{2}$

0.68 or $68 \%$ 
Figure 4. Increase in exterior surface area relative to a 1:1 aspect ratio.

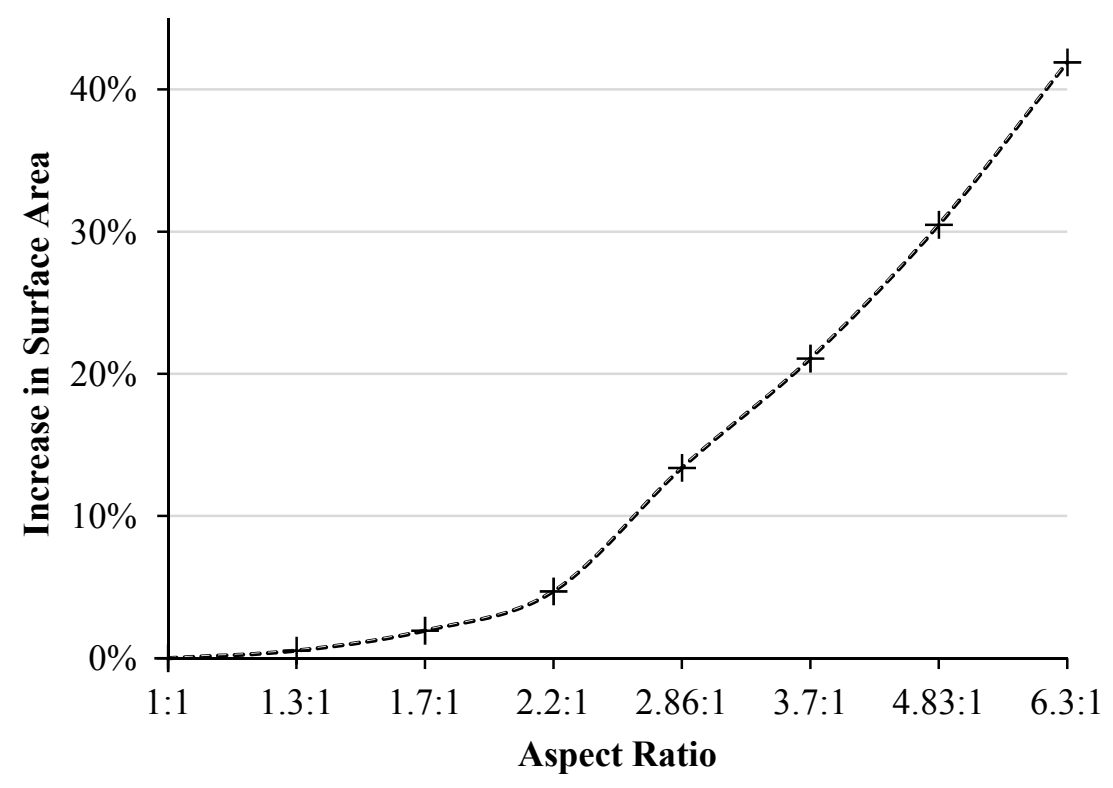

Figure 5. Exterior wall surface area per square meter of floor area for various building footprints with an assumed floor to floor height of $3 \mathrm{~m}$.

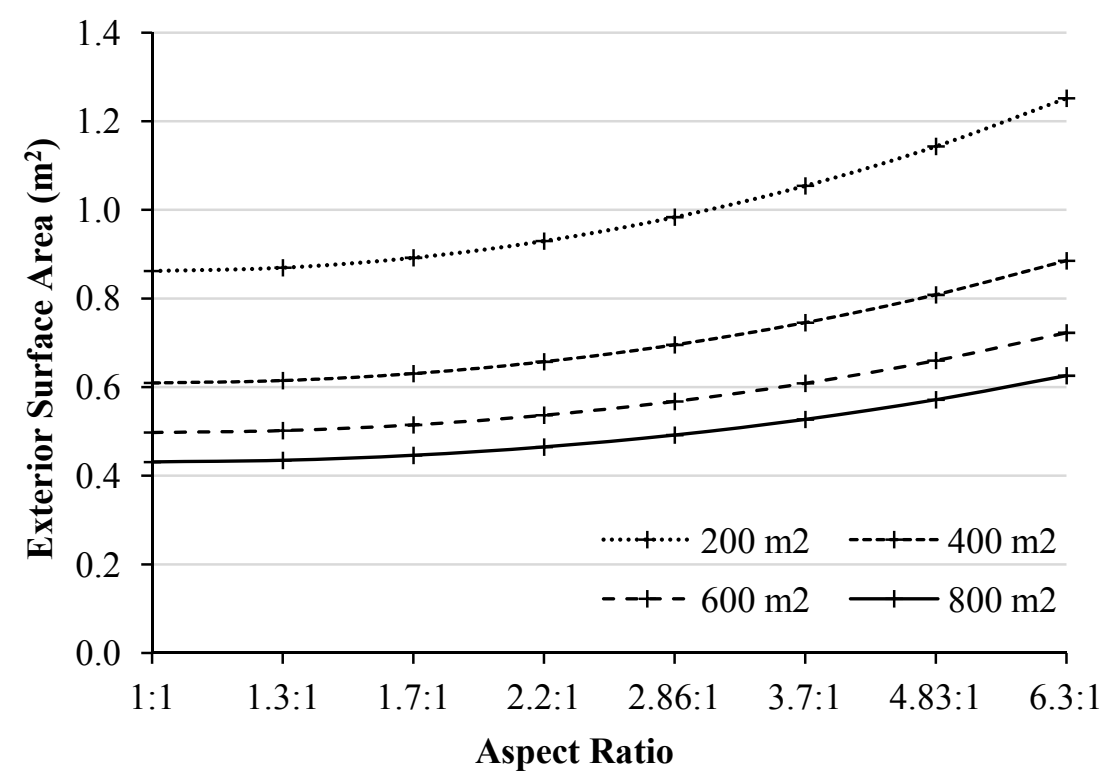

\subsection{The Envelope: Conduction}

Within the constraint of cost and practicality, we strive to reduce the amount of heat transfer by the use of sufficient insulation, which lowers the conductivity. It is also important to note that the total quantity of heat transferred by conduction is largely dependent on area (Equation (1)).

$$
Q_{\text {conduction }}=\frac{A \cdot k}{L} \cdot \Delta T
$$




\subsection{The Envelope: Convection}

The infiltration of air in the building envelope is a major source of heat loss and gain. A leaky enclosure can result in the need to supply significantly more heat during winter months. A recent MURB energy audit conducted by RDH Building Consultants revealed that leaky MURBs in Vancouver could result in upwards of a $20 \%$ heat loss annually [5]. The United States Department of Energy (DOE) has indicated that up to $40 \%$ of energy consumed to heat or cool a building is a result of air leakage [7]. Currently, a minimum standard for the airtightness of building envelopes does not exist in building code requirements, but its impact on energy efficiency is essential. Residential buildings tend to have less internal heat gains, and the enclosure is more important in maintaining the internal environment temperature efficiently [4].

Air leakage is inevitable in buildings, particularly in high-rises, where the stack effect and wind pressures may be considerably higher. The rate of air leakage depends on the air pressure differential between the interior and exterior. Air can hold a significant amount of energy, particularly humid interior air, due to its high heat capacity (Equation (2)).

$$
Q_{\text {convection }}=C_{o} \cdot \rho \cdot \frac{d V}{d t} \cdot \Delta T
$$

The total air leakage rate, however, is also dependent on the air tightness and surface area of the building envelope. Correspondingly, a lower exterior surface area generally permits less total air leakage.

\subsection{Solar Radiation}

The south facade can receive more than twice the heat gain of east and west facades in the winter. Yet, the east and west facades have significant impacts on overall heat gain in the summer months, as seen in Figure 6. Solar radiation can be harnessed to reduce the consumption for heating by altering the building aspect ratio [8].

Figure 6. Clear sky solar gain on wall surfaces at $45^{\circ}$ latitude [4].

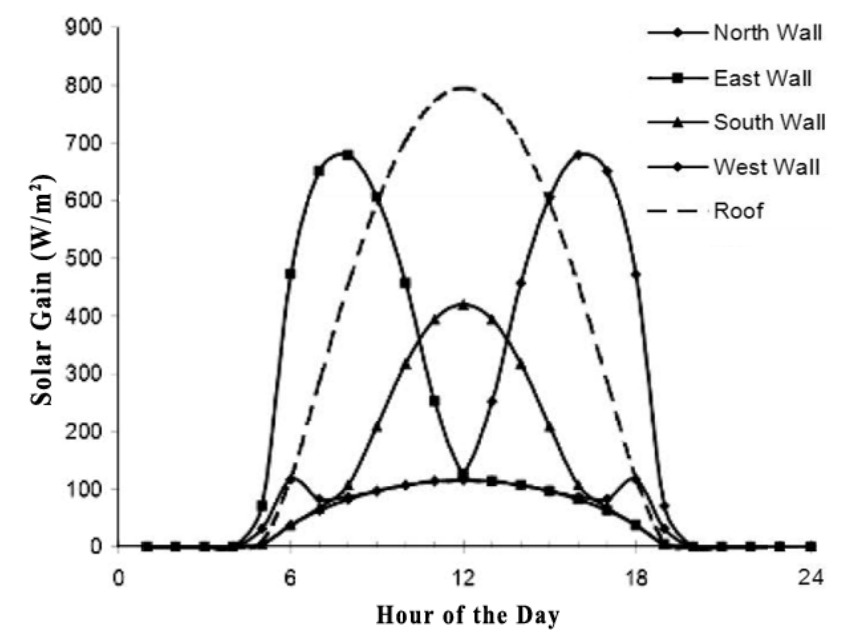

Summer Solstice (July 21)

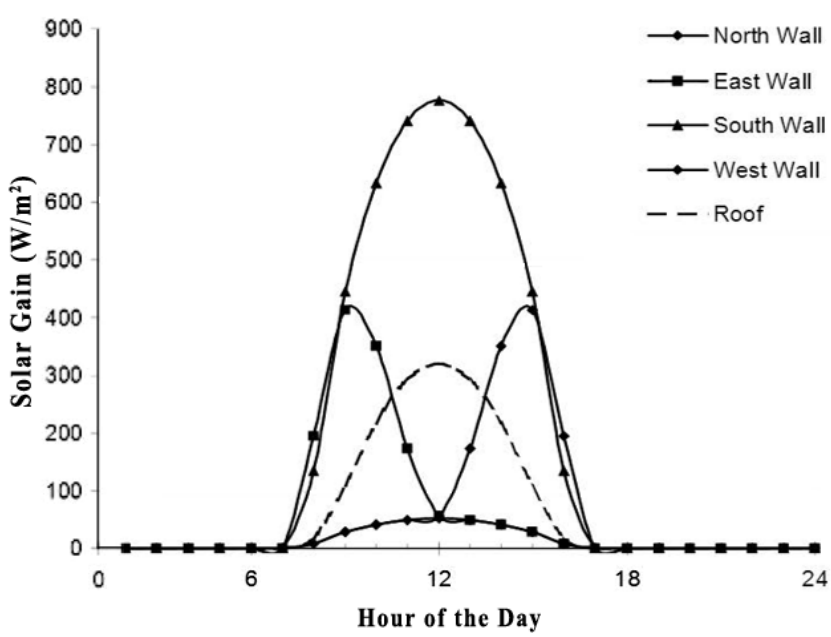

Winter Solstice (December 21) 


\section{Methodology}

A number of buildings were designed and simulated in the eQUEST energy simulation software [9]. These models were evaluated based on climatic data to determine the relationship between aspect ratio and energy efficiency. A base model was developed, and permutations on the aspect ratio were created to produce varying building geometries of different aspect ratios.

\subsection{Building Design}

The simulation models are designed to represent typical configurations of new and existing residential buildings. It must be noted that the quality of space within buildings varies amongst building footprints, with some allowing for more livable space, less circulation and better distribution of building services. This variable is considered in the building models, so that each has the same quantity of floor area, livable space and circulation space. The wall surface area varies with different aspect ratios, but the floor area is maintained between all simulation models. This is important to form a proper basis of comparison.

\subsection{Plan Design}

The models characterize ten-storey buildings with a gross floor area of $6000 \mathrm{~m}^{2}$. Each floor is divided into eight suites with an area of $524 \mathrm{~m}^{2}$ of livable space and a central corridor of $76 \mathrm{~m}^{2}$ (Figure 7). The suites vary in size between approximately $55 \mathrm{~m}^{2}$ and $75 \mathrm{~m}^{2}$ and an approximate occupant load of two people. This is representative of many newly constructed MURBs, which have an average floor area of $74.3 \mathrm{~m}^{2}$ [10]. In building design, useable space is clearly affected by the layout of the building, and certain designs will utilize circulation space more efficiently. All building layouts utilize a central circulation corridor comprising $10 \%$ of the floor plate area.

Figure 7. Model floor plans have consistent livable and circulation space and are representative of typical modern multi-unit residential building (MURB) layouts.

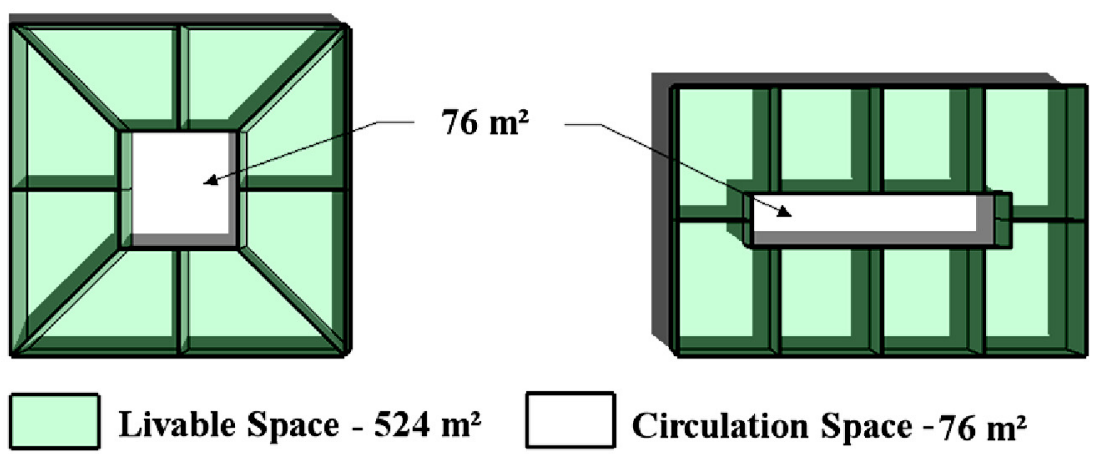

The baseline design, Profile A, was established, and further permutations were modeled. Profile B through $G$ have an increasing aspect ratio along the east-west axis. These building types were simulated with two orientations along the east-west axis and north-south axis (Figure 8). For Building Profile A, a single orientation was used, as its aspect ratio of $1: 1$ is not changed by a $90^{\circ} \theta$ rotation. Thus, a total of 13 building models were simulated in cities across Canada, including Vancouver, 
Calgary, Toronto, Montreal and Halifax (Table 1). A noticeable result of orientation and aspect ratio is the change in the amount of shading and solar gain surfaces.

Figure 8. A $90^{\circ}$ rotation of building models along the axis inverts the aspect ratio when defined with $\mathrm{x}, \mathrm{y}$ coordinates.

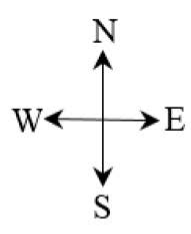

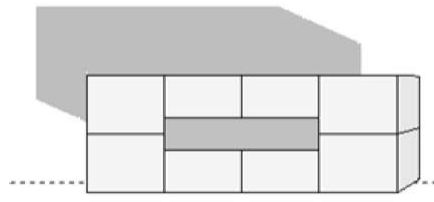

Profile C, aspect ratio 2.7:1

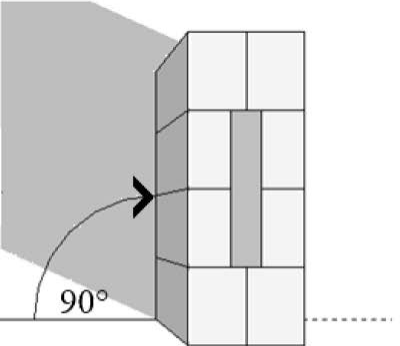

Profile $\mathrm{C} 90^{\circ} \theta$, aspect ratio $1: 2.7$

Table 1. Model simulation geometry.

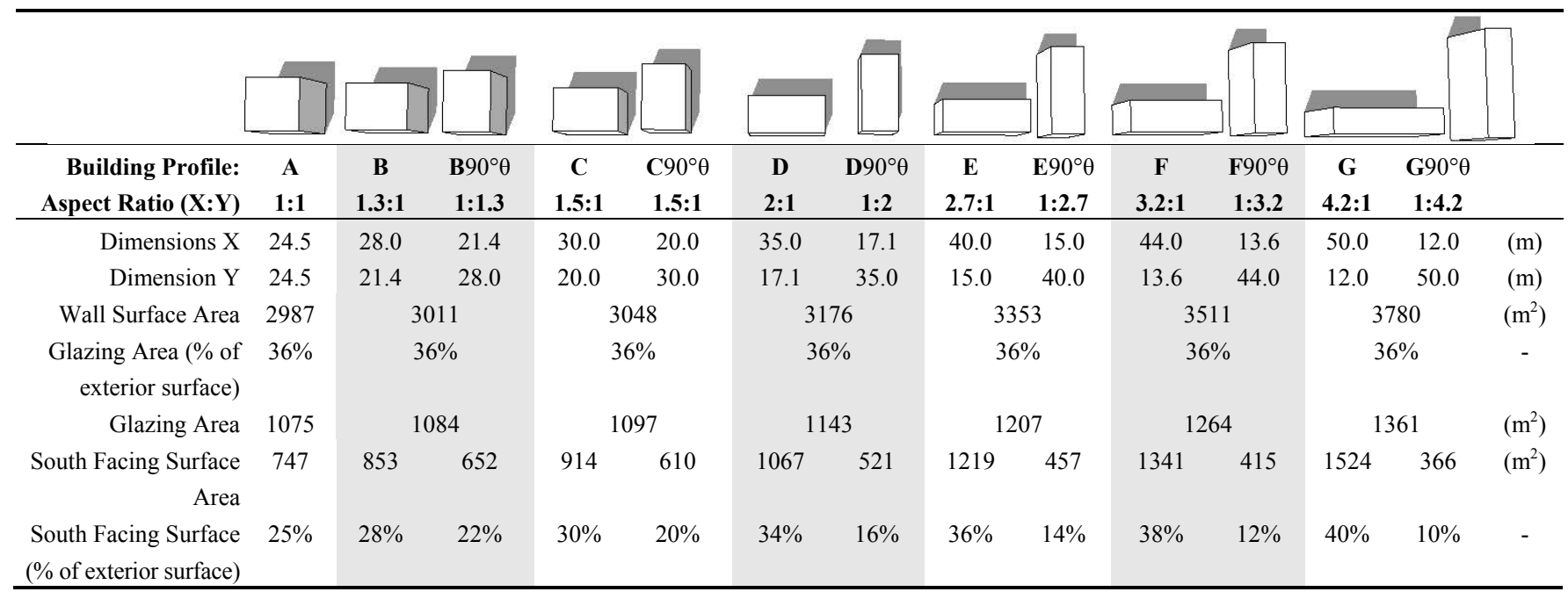

\subsection{Construction Parameters}

To properly evaluate the significance of aspect ratio on energy performance, it is important to isolate the many variables that buildings by their unique nature exhibit. Parameters, such as insulation, were selected to represent a typical residential building constructed during the present time in Toronto, moderately above the prescriptive requirements regarding insulation of ASHRAE 90.12007 for Climate Zone 6 [11]. The Emissivity, thermal resistance, interior temperature set-points, occupant and equipment loads, etc., are modeled after what represents a perceived typical or common MURB of current construction standards.

The recommended ventilation provided to occupants can have a large impact on energy consumption. Studies evaluating MURBs in Canada have recommended balancing occupant air quality and operating cost, by supplying air at a rate of $7.5 \mathrm{~L} / \mathrm{s}$ [12]. These parameters selected reflect what can be readily achieved in modern construction and are listed in Table 2. 
Table 2. Model simulation parameters.

\begin{tabular}{|c|c|c|c|c|}
\hline \multicolumn{5}{|l|}{ Envelope } \\
\hline Component & \multicolumn{2}{|c|}{ Description } & U Value $\left(W / \mathbf{m}^{2} K\right)$ & Emissivity \\
\hline Exterior Wall: & \multicolumn{2}{|c|}{$\begin{array}{l}\text { Aluminum and Glass Spandrel with batt insulation, } \\
\text { metal frame }\end{array}$} & 0.364 & 0.6 \\
\hline Roof: & \multicolumn{2}{|c|}{ Built up roof, polyurethane insulation } & 0.155 & 0.6 \\
\hline Ground Floor: & \multicolumn{4}{|c|}{ Earth contact with insulated footings } \\
\hline Glazing: & \multicolumn{2}{|c|}{$\begin{array}{l}\text { Double pane, Low emissivity with argon gas } \\
\text { (Glass Type Code: } 2642 \text { ) }\end{array}$} & 0.3 & 0.1 \\
\hline & \multicolumn{4}{|c|}{ Solar Heat Gain Coeff.: 0.75, Solar Transmittance: 0.54} \\
\hline Floor: & \multicolumn{4}{|c|}{ Concrete slab $(150 \mathrm{~mm})$} \\
\hline \multicolumn{5}{|l|}{ HVAC } \\
\hline Component & \multicolumn{4}{|c|}{ Description } \\
\hline Terminal: & \multicolumn{4}{|c|}{ Fan Coil Unit (four pipe) } \\
\hline Thermostat: & \multicolumn{2}{|c|}{ Heating Set Point: $20^{\circ} \mathrm{C}$} & \multicolumn{2}{|c|}{ Cooling Set Point: $25.6^{\circ} \mathrm{C}$} \\
\hline Cooling Plant: & \multicolumn{2}{|c|}{ Centrifugal Hermetic Chiller } & \multicolumn{2}{|c|}{ Autosized between 150 and 299 tons } \\
\hline & \multicolumn{2}{|c|}{ Fuel Source: Electricity } & \multicolumn{2}{|c|}{ Coefficient of performance: 4.6} \\
\hline Heating Plant: & \multicolumn{2}{|c|}{ Boiler (natural draft) } & \multicolumn{2}{|l|}{ Autosized } \\
\hline & \multicolumn{2}{|c|}{ Fuel Source: Natural Gas } & \multicolumn{2}{|l|}{ Efficiency: $80 \%$} \\
\hline \multicolumn{5}{|c|}{ Supply Ventilation: $7.5 \mathrm{~L} / \mathrm{s}$ per person $\left(\sim 0.4 \mathrm{~L} / \mathrm{s}\right.$ per $\left.\mathrm{m}^{2}\right)$} \\
\hline \multicolumn{5}{|c|}{ Internal Load and Schedule } \\
\hline \multirow{3}{*}{\multicolumn{2}{|c|}{$\begin{array}{l}\text { People Density: } 200 \mathrm{~m}^{2} / \mathrm{p} \\
\text { Weekday Schedule: }\end{array}$}} & Lighting Load: $10.8 \mathrm{~W} / \mathrm{m}^{2}$ & \multirow{3}{*}{\multicolumn{2}{|c|}{ Equipment Load: $7.0 \mathrm{~W} / \mathrm{m}^{2}$}} \\
\hline & & Return at: 4 PM & & \\
\hline & & Leave at: 9 AM & & \\
\hline
\end{tabular}

In field reviews of over 200 MURBs across Canada and the United States, the average air infiltration was found to be approximately $3.76 \mathrm{~L} / \mathrm{s} \cdot \mathrm{m}^{2}$ at $75 \mathrm{~Pa}$. The buildings varied greatly in age, and it was noted to be a significant factor in the results, with newer building envelopes yielding less infiltration. Despite a relatively poor air infiltration of existing MURBs, creating an air tight enclosure is a lot easier to achieve in current construction [13]. A number of standards exist defining air tightness at specific pressures. ASHRAE defines buildings with an infiltration rate greater than $3.0 \mathrm{~L} /\left(\mathrm{s} \cdot \mathrm{m}^{2}\right)$ at $75 \mathrm{~Pa}$ as "leaky" and $1.50 \mathrm{~L} /\left(\mathrm{s} \cdot \mathrm{m}^{2}\right)$ at $75 \mathrm{~Pa}$ as "average" [14]. The selected air tightness parameters are reflective of what can be achieved readily in modern construction (Table 3 ).

Table 3. Air infiltration rates.

\begin{tabular}{cccc}
\hline Air Tightness Reference & \multicolumn{3}{c}{ Infiltration Rate L/(s· m $\mathbf{2}^{2}$ at } \\
& $\mathbf{7 5 ~ P a}$ & $\mathbf{5 0 ~ P a}$ & $\mathbf{5 ~ P a}$ \\
\hline ASHRAE "Leaky" [14] & 3.00 & 2.40 & 0.510 \\
ASHRAE “Average” [14] & 1.50 & 1.20 & 0.255 \\
ASHRAE "Tight” [14] & 0.50 & 0.40 & 0.085 \\
Average MURB in Canada [13] & 3.76 & 3.01 & 0.638 \\
\hline Selected for simulation & 1.18 & 0.94 & 0.200 \\
\hline
\end{tabular}




\subsection{Climatic Data}

The building simulations are conducted in multiple cities in Canada to determine the energy impact in regards to geographical location. Cities across Canada are considered to exist in a cold climate. However, despite being of a similar latitude, the variations of regional climate in regards to humidity, precipitation, solar gain and seasonal extremes are large and impact building efficiency greatly. These cities, to varying extents, house significant and growing population in MURBs.

A significant difference in heating and cooling between the cities is noted by the difference in heating degree days (HDD) and cooling degree days (CDD). Due to its marine climate, Vancouver is known to have low energy consumption for heating and cooling compared to most cities in Canada. It has mild summers and winters, where extreme temperatures are not common. Toronto has $33 \%$ more HDD and over 500\% more CDD as Vancouver (Table 4) [15]. Calgary, has a high heating demand, but a contrastingly low cooling demand.

Table 4. Average annual heating and cooling degree days in Canadian cities (1971-2000) [15].

\begin{tabular}{cccccc}
\hline Climatic Attributes & Vancouver & Calgary & Toronto & Montreal & Halifax \\
\hline Heating Degree Days & 2926 & 4948 & 4066 & 4575 & 4367 \\
Cooling Degree Days & 44 & 44 & 252 & 235 & 104 \\
Climatic Region [16] & \multirow{2}{*}{ wet, cool } & dry, & moderately wet, & moderately wet, & wet and cold \\
\hline
\end{tabular}

\section{Results and Discussion}

Energy consumption from heating and cooling vary significantly between the 13 simulated building aspect ratios. For the MURBs simulated, the optimal aspect ratios were generally found to be between Profile A, 1:1, and Profile E, 2.7:1. However, it is noted that the optimal aspect ratio for heating efficiency is not necessarily optimal for cooling efficiency, as seen in the Toronto simulation monthly heating and cooling consumption (Figures 9 and 10). Thus, the optimal building geometry will form a balance between the two energy demands. As expected in a cold climate country, the total energy consumption is heavily weighted on the heating demand. The value of this weighting varies significantly depending on factors such as energy source, location and economics.

\subsection{Detail Monthly Analysis of Toronto}

A detailed look at energy consumption for aspect ratios in Toronto reveals insight to optimal building geometries and the potential reductions in energy consumption. The monthly energy consumption for heating and cooling is in Figures 9 and 10, illustrating the increased significance of aspect ratio during the seasonal extremes. During peak demand months, energy consumption between the optimal and least optimal aspect ratio varies as much as $34 \%$ for both heating and cooling. Energy consumption for cooling decreases when the aspect ratio is increased from 1:1 along the east-west axis. This reduction in cooling loads continues, until it reaches an optimal aspect ratio. At this point, any further increase in aspect ratio results in increased energy consumption. Aspect ratios were determined to be optimal between $1: 1$ and 1.5:1 for heating and between 1.5:1 and 2.7:1 for cooling. 
Figure 9. Monthly heating consumption for different aspect ratios in Toronto.

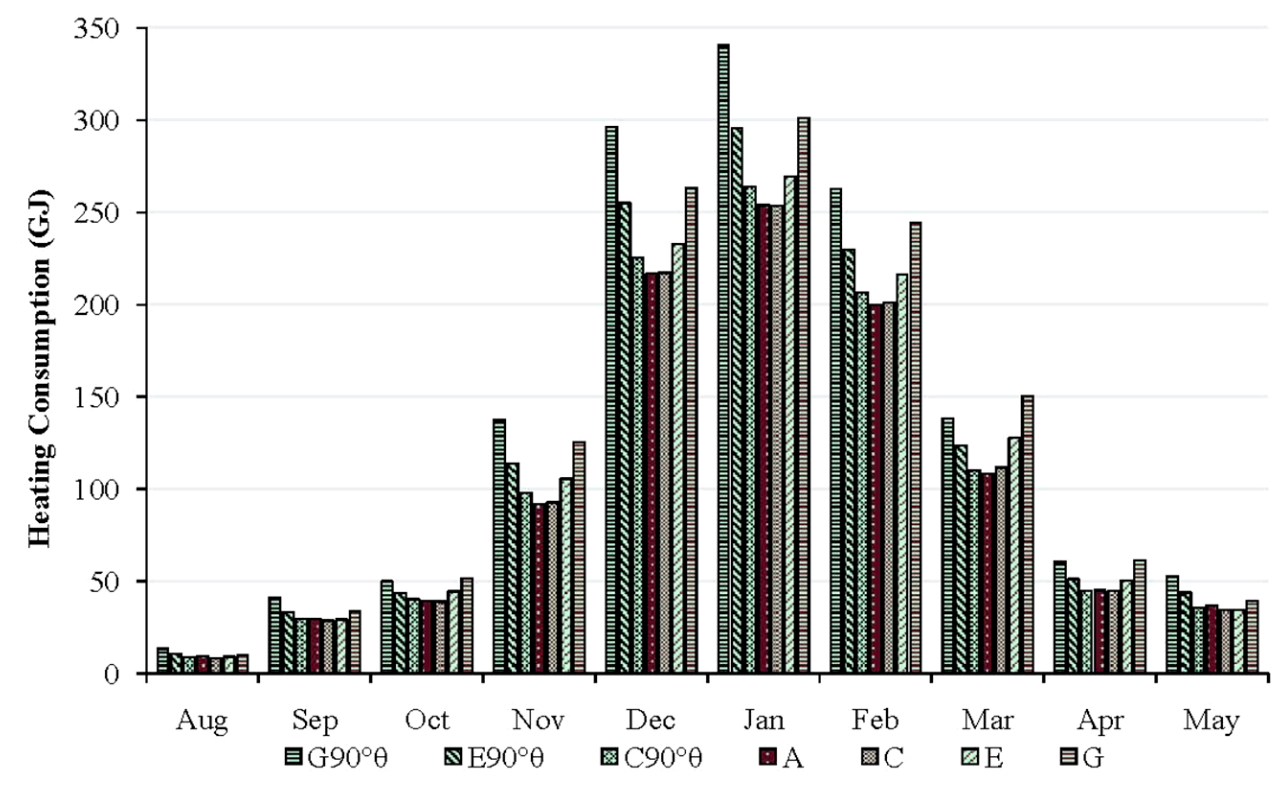

Figure 10. Monthly cooling consumption for different aspect ratios in Toronto.

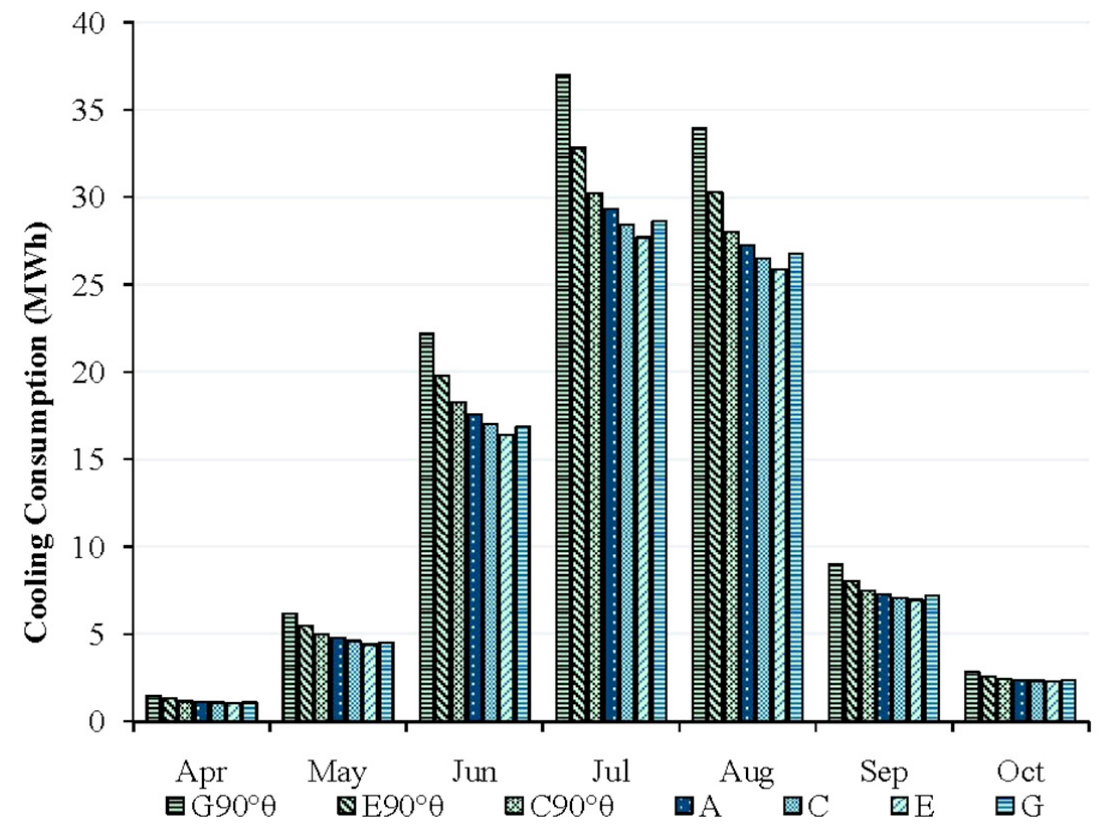

\subsection{Detail Monthly Analysis of Toronto: Heating}

Energy consumption was reduced between Profile A, 1:1, to Profile C, 1.5:1. Any increase in aspect ratio away from this range yielded increased energy consumption. Increasing the aspect ratio $90^{\circ}$ perpendicular to the east-west axis resulted in significantly increased consumption. Profile $690^{\circ} \theta$ consumed 13\% more than Profile G. The larger aspect ratios consumed more energy for heating; however, those oriented along the east-west axis benefited from increased solar gain during winter months, minimizing the impact (Figure 9). 


\subsection{Monthly Analysis: Cooling}

For cooling, the optimal aspect ratio is seen to incorporate a larger range than that for heating. The lowest monthly cooling demand was of Profile E, 2.7:1. The building orientation had a significant impact on the larger aspect ratios (Figure 10).

- Along the east-west axis, the increase of aspect ratio decreases energy consumption. Amongst these profiles, cooling consumption was highest for Profile A. The optimal aspect ratio was Profile E, which required 27.7 MWh of cooling during the peak month of July. This is a 5.5\% decrease in cooling consumption compared to Profile A, at 29.3 MWh;

- The orientation of profiles $90^{\circ}$ to the east-west axis had a large impact. In July, Profile G90 ${ }^{\circ}$ consumed 37.0 MWh. This marks a 29\% increase in energy consumption from Profile G of 28.6 MWh. Whereas Profile A was the least efficient of the profiles oriented along the east-west axis, it was more efficient that all profiles oriented along the north-south axis.

Plotting the energy consumption of Profile $G 90^{\circ} \theta$ (1:4.2) and Profile C (1.5:1) illustrates possible ranges of energy consumptions that may be encountered for aspect ratios under 4.2:1 for a typical MURB (Figure 11). Peak demand also occurs during the seasonal extremes. This is of great importance in regards to the design and sizing of heating and cooling systems, which affects capital cost, operating efficiency and durability [17].

Figure 11. Comparison of energy consumption between Profile $B$ and Profile $D 90^{\circ} \theta$ for Toronto simulations.

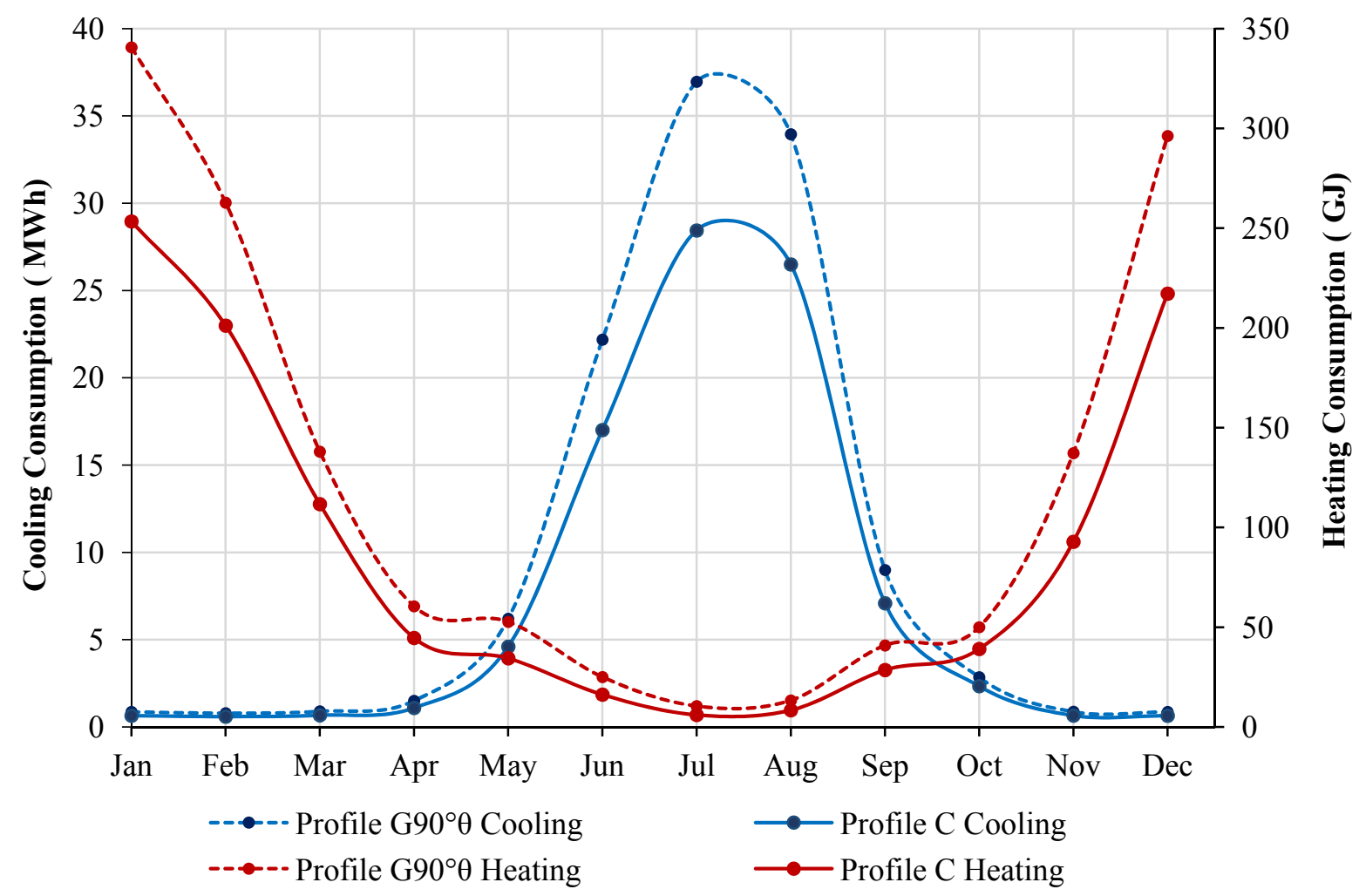




\subsection{Annual Energy Consumption Analysis}

Energy simulations for Vancouver, Calgary, Toronto, Montreal and Halifax demonstrated a varying impact of aspect ratio on energy consumption. The results were compared amongst heating, cooling and combined energy consumption, as seen in Table 5. Similar trends were observed regarding optimal aspect ratios for all locations. The increase and decrease in consumption can be compared amongst aspect ratios and their respective locations. The relative energy consumption (REC) of different profiles can be determined by dividing the energy consumed for a particular aspect ratio by the energy consumption of a 1:1 aspect ratio (Equation (3)). Thus, an REC that is negative indicates a decrease in energy consumption, and a positive REC indicates an increase.

$$
R E C=\left(\frac{E_{\text {aspect }}}{E_{1: 1}}-1\right) \%
$$

Table 5. Model simulation results: total annual energy consumption. REC, relative energy consumption.

\begin{tabular}{|c|c|c|c|c|c|c|c|c|c|c|c|c|c|c|}
\hline $\begin{array}{l}\text { Aspect Ratio (x:y) } \\
\text { Building Profile: }\end{array}$ & $\begin{array}{c}1: 4.2 \\
\mathbf{G} 90^{\circ} \theta \\
\end{array}$ & $\begin{array}{c}1: 3.2 \\
\text { F } 90^{\circ} \theta \\
\end{array}$ & $\begin{array}{c}1: 2.7 \\
\mathbf{E} 90^{\circ} \theta \\
\end{array}$ & $\begin{array}{c}1: 2 \\
\text { D } 90^{\circ} \theta \\
\end{array}$ & $\begin{array}{r}1.5: 1 \\
\operatorname{C}^{\circ} 0^{\circ} \theta \\
\end{array}$ & $\begin{array}{c}1: 1.3 \\
\text { B } 90^{\circ} \theta \\
\end{array}$ & $\begin{array}{c}1: 1 \\
\mathbf{A}\end{array}$ & $\begin{array}{c}1.3: 1 \\
\text { B }\end{array}$ & $\begin{array}{c}1.5: 1 \\
\mathbf{C}\end{array}$ & $\begin{array}{c}2: 1 \\
\mathbf{D}\end{array}$ & $\begin{array}{c}2.7: 1 \\
\mathbf{E}\end{array}$ & $\begin{array}{c}3.2: 1 \\
\mathbf{F}\end{array}$ & $\begin{array}{c}4.2: 1 \\
\mathbf{G}\end{array}$ & \\
\hline \multicolumn{15}{|l|}{ Montreal } \\
\hline \multirow[t]{2}{*}{ Cooling Consumption } & 133.6 & 127.0 & 119.3 & 113.3 & 107.8 & 104.7 & 103.2 & 101.5 & 100.5 & 94.6 & 94.9 & 97.2 & 98.6 & $(\mathrm{MWh})$ \\
\hline & 481.1 & 457.0 & 429.5 & 408.0 & 388.2 & 377.0 & 371.5 & 365.5 & 361.7 & 340.7 & 341.6 & 349.9 & 355.1 & (GJ) \\
\hline Heating Consumption & 1554 & 1461 & 1389 & 1315 & 1236 & 1213 & 1198 & 1188 & 1195 & 1243 & 1286 & 1355 & 1416 & (GJ) \\
\hline REC & $29.7 \%$ & $21.9 \%$ & $15.9 \%$ & $9.8 \%$ & $3.2 \%$ & $1.2 \%$ & $0.0 \%$ & $-0.9 \%$ & $-0.2 \%$ & $3.7 \%$ & $7.3 \%$ & $13.1 \%$ & $18.2 \%$ & \\
\hline $\begin{array}{r}\text { Combined Energy } \\
\text { Consumption }\end{array}$ & 2035 & 1918 & 1818 & 1723 & 1624 & 1590 & 1569 & 1553 & 1557 & 1584 & 1628 & 1705 & 1771 & (GJ) \\
\hline REC & $29.6 \%$ & $22.2 \%$ & $15.8 \%$ & $9.8 \%$ & $3.5 \%$ & $1.3 \%$ & $0.0 \%$ & $-1.0 \%$ & $-0.8 \%$ & $0.9 \%$ & $3.7 \%$ & $8.7 \%$ & $12.9 \%$ & \\
\hline \multicolumn{15}{|l|}{ Vancouver } \\
\hline \multirow[t]{2}{*}{ Cooling Consumption } & 41.2 & 39.1 & 36.5 & 34.4 & 32.9 & 32.0 & 31.5 & 31.2 & 30.9 & 30.6 & 30.6 & 31.1 & 31.1 & (MWh) \\
\hline & 148.5 & 140.8 & 131.5 & 124.0 & 118.6 & 115.4 & 113.4 & 112.2 & 111.3 & 110.2 & 110.2 & 112.1 & 111.8 & (GJ) \\
\hline \multirow{2}{*}{$\begin{array}{r}\text { Heating Consumption } \\
\text { REC }\end{array}$} & 911 & 836 & 775 & 722 & 672 & 659 & 641 & 637 & 637 & 664 & 697 & 746 & 793 & (GJ) \\
\hline & $42.1 \%$ & $30.4 \%$ & $20.8 \%$ & $12.6 \%$ & $4.8 \%$ & $2.8 \%$ & $0.0 \%$ & $-0.7 \%$ & $-0.7 \%$ & $3.5 \%$ & $8.6 \%$ & $16.3 \%$ & $23.7 \%$ & \\
\hline $\begin{array}{r}\text { Combined Energy } \\
\text { Consumption }\end{array}$ & 1060 & 977 & 907 & 846 & 791 & 775 & 755 & 749 & 748 & 774 & 807 & 858 & 905 & (GJ) \\
\hline REC & $40.4 \%$ & $29.5 \%$ & $20.1 \%$ & $12.1 \%$ & $4.8 \%$ & $2.7 \%$ & $0.0 \%$ & $-0.7 \%$ & $-0.9 \%$ & $2.5 \%$ & $6.9 \%$ & $13.7 \%$ & $19.9 \%$ & \\
\hline \multicolumn{15}{|l|}{ Halifax } \\
\hline \multirow[t]{2}{*}{ Cooling Consumption } & 48.0 & 46.3 & 43.4 & 41.2 & 38.6 & 37.6 & 37.3 & 36.9 & 36.5 & 36.2 & 36.1 & 36.7 & 36.6 & (MWh) \\
\hline & 172.9 & 166.7 & 156.4 & 148.4 & 139.1 & 135.4 & 134.2 & 132.9 & 131.5 & 130.2 & 129.9 & 132.2 & 131.7 & (GJ) \\
\hline \multirow{2}{*}{$\begin{array}{r}\text { Heating Consumption } \\
\text { REC }\end{array}$} & 1492 & 1381 & 1315 & 1236 & 1163 & 1139 & 1128 & 1120 & 1127 & 1171 & 1216 & 1282 & 1365 & (GJ) \\
\hline & $32.2 \%$ & $22.4 \%$ & $16.6 \%$ & $9.6 \%$ & $3.1 \%$ & $1.0 \%$ & $0.0 \%$ & $-0.7 \%$ & $-0.1 \%$ & $3.8 \%$ & $7.8 \%$ & $13.7 \%$ & $21.0 \%$ & \\
\hline $\begin{array}{r}\text { Combined Energy } \\
\text { Consumption }\end{array}$ & 1665 & 1547 & 1471 & 1384 & 1302 & 1274 & 1262 & 1253 & 1259 & 1302 & 1346 & 1415 & 1496 & (GJ) \\
\hline REC & $31.9 \%$ & $22.6 \%$ & $16.6 \%$ & $9.7 \%$ & $3.1 \%$ & $1.0 \%$ & $0.0 \%$ & $-0.7 \%$ & $-0.3 \%$ & $3.1 \%$ & $6.6 \%$ & $12.1 \%$ & $18.5 \%$ & \\
\hline \multicolumn{15}{|l|}{ Calgary } \\
\hline \multirow[t]{2}{*}{ Cooling Consumption } & 75.8 & 72.1 & 67.6 & 63.8 & 60.3 & 58.5 & 57.5 & 56.3 & 55.3 & 54.8 & 54.8 & 55.8 & 56.4 & $(\mathrm{MWh})$ \\
\hline & 272.7 & 259.7 & 243.2 & 229.6 & 217.0 & 210.7 & 207.1 & 202.8 & 199.2 & 197.2 & 197.3 & 201.0 & 203.0 & (GJ) \\
\hline \multirow{2}{*}{$\begin{array}{r}\text { Heating Consumption } \\
\text { REC }\end{array}$} & 1748 & 1534 & 1450 & 1366 & 1281 & 1254 & 1235 & 1221 & 1226 & 1270 & 1318 & 1387 & 1560 & (GJ) \\
\hline & $41.6 \%$ & $24.3 \%$ & $17.5 \%$ & $10.6 \%$ & $3.8 \%$ & $1.6 \%$ & $0.0 \%$ & $-1.1 \%$ & $-0.7 \%$ & $2.9 \%$ & $6.8 \%$ & $12.4 \%$ & $26.3 \%$ & \\
\hline $\begin{array}{r}\text { Combined Energy } \\
\text { Consumption }\end{array}$ & 2021 & 1794 & 1694 & 1595 & 1498 & 1465 & 1442 & 1424 & 1425 & 1467 & 1516 & 1588 & 1763 & (GJ) \\
\hline REC & $40.1 \%$ & $24.4 \%$ & $17.5 \%$ & $10.6 \%$ & $3.9 \%$ & $1.6 \%$ & $0.0 \%$ & $-1.2 \%$ & $-1.2 \%$ & $1.8 \%$ & $5.1 \%$ & $10.2 \%$ & $22.3 \%$ & \\
\hline
\end{tabular}


Table 5. Cont.

\begin{tabular}{|c|c|c|c|c|c|c|c|c|c|c|c|c|c|c|}
\hline Aspect Ratio (x:y) & $1: 4.2$ & $1: 3.2$ & $1: 2.7$ & $1: 2$ & $1.5: 1$ & $1: 1.3$ & $1: 1$ & $1.3: 1$ & $1.5: 1$ & $2: 1$ & $2.7: 1$ & $3.2: 1$ & $4.2: 1$ & \\
\hline Building Profile: & $\mathbf{G} 90^{\circ} \theta$ & $\mathbf{F} 90^{\circ} \theta$ & $\mathbf{E} 90^{\circ} \theta$ & D9 $90^{\circ} \theta$ & $\mathrm{C} 90^{\circ} \theta$ & B $90^{\circ} \theta$ & $\mathbf{A}$ & B & C & D & $\mathbf{E}$ & $\mathbf{F}$ & G & \\
\hline \multicolumn{15}{|l|}{ Toronto } \\
\hline \multirow[t]{2}{*}{ Cooling Consumption } & 116.9 & 111.5 & 104.1 & 99.9 & 96.0 & 93.6 & 92.9 & 91.9 & 91.0 & 90.5 & 89.4 & 91.3 & 91.1 & $(\mathrm{MWh})$ \\
\hline & 421.0 & 401.2 & 374.8 & 359.8 & 345.8 & 337.1 & 334.6 & 330.7 & 327.5 & 325.9 & 321.7 & 328.5 & 328.1 & (GJ) \\
\hline \multirow{2}{*}{$\begin{array}{r}\text { Heating Consumption } \\
\text { REC }\end{array}$} & 1428 & 1303 & 1230 & 1157 & 1087 & 1063 & 1056 & 1048 & 1054 & 1100 & 1143 & 1211 & 1308 & (GJ) \\
\hline & $35.2 \%$ & $23.4 \%$ & $16.5 \%$ & $9.6 \%$ & $3.0 \%$ & $0.7 \%$ & $0.0 \%$ & $-0.8 \%$ & $-0.2 \%$ & $4.1 \%$ & $8.2 \%$ & $14.7 \%$ & $23.9 \%$ & \\
\hline \multirow{2}{*}{$\begin{array}{r}\text { Combined Energy } \\
\text { Consumption } \\
\text { REC }\end{array}$} & 1849 & 1705 & 1604 & 1517 & 1433 & 1400 & 1391 & 1378 & 1381 & 1425 & 1464 & 1540 & 1636 & (GJ) \\
\hline & $33.0 \%$ & $22.6 \%$ & $15.4 \%$ & $9.1 \%$ & $3.0 \%$ & $0.7 \%$ & $0.0 \%$ & $-0.9 \%$ & $-0.6 \%$ & $2.5 \%$ & $5.3 \%$ & $10.7 \%$ & $17.6 \%$ & \\
\hline
\end{tabular}

\subsection{Annual Energy Consumption Analysis: Heating}

By comparing the energy consumption along the corresponding aspect ratios, trends are observed in all locations. Heating consumption is reduced from orientations along the east-west axis compared to those oriented perpendicular. In both cases, the consumption generally increases when moving away from a $1: 1$ aspect ratio. However, it is noted that Profile B (1.3:1) and Profile C (1.5:1) consumed slightly less than Profile A in all cases by under 2\%. Profiles A, B and C can be considered optimal in regards to heating, due to their close REC (Figures 12 and 13).

The REC is seen to increase rapidly beyond an aspect ratio of $1: 1$ to $1.5: 1$. The increase in consumption is most significant in Profile G90 $\theta$ with an increase of $29 \%-42 \%$ REC for all locations. This is compared to Profile D, with an increase of $18 \%-26 \%$ REC for all locations.

Figure 12. Annual heating consumption for aspect ratios in Canadian cities.

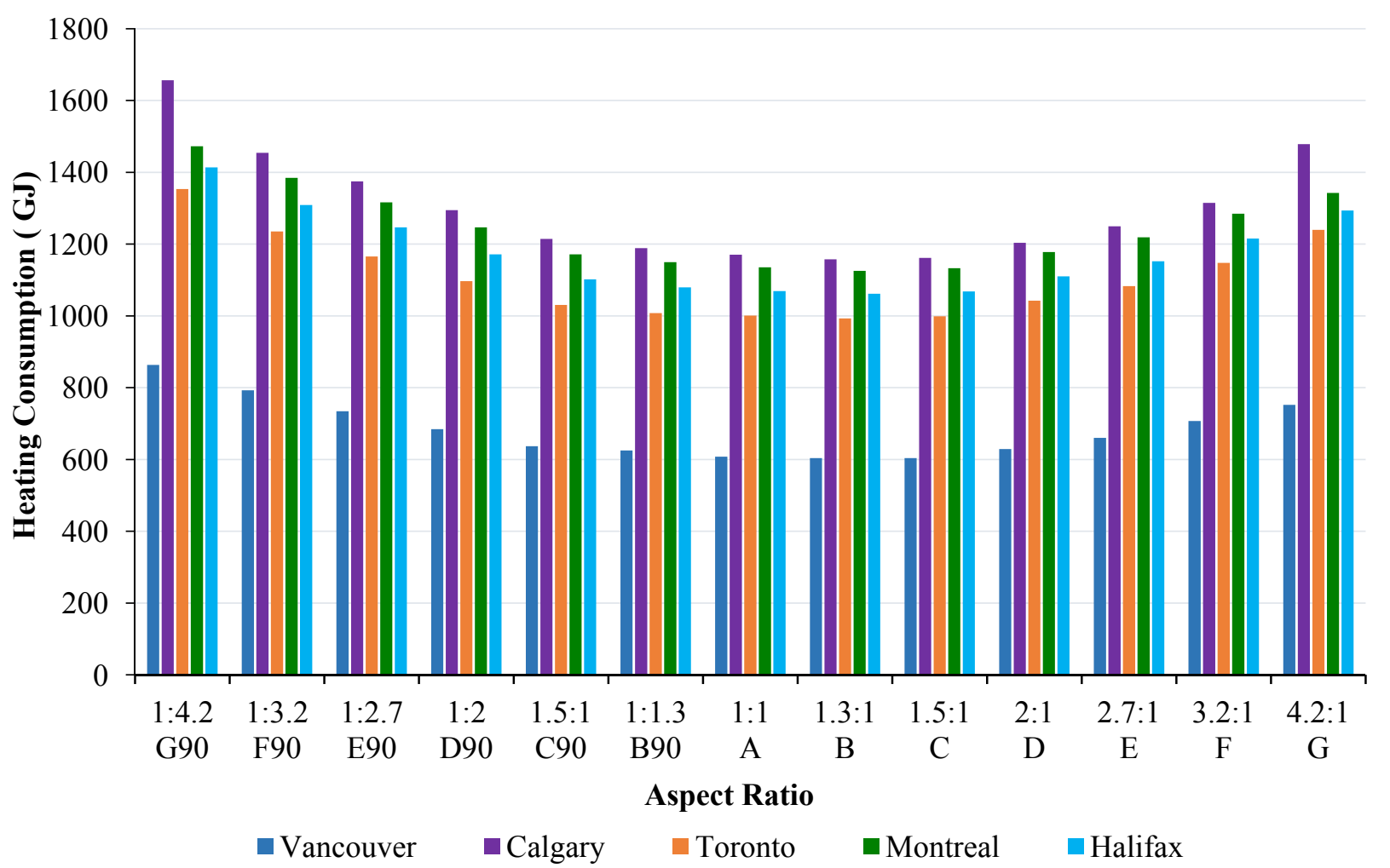


Figure 13. Relative energy consumption in heating for aspect ratios.

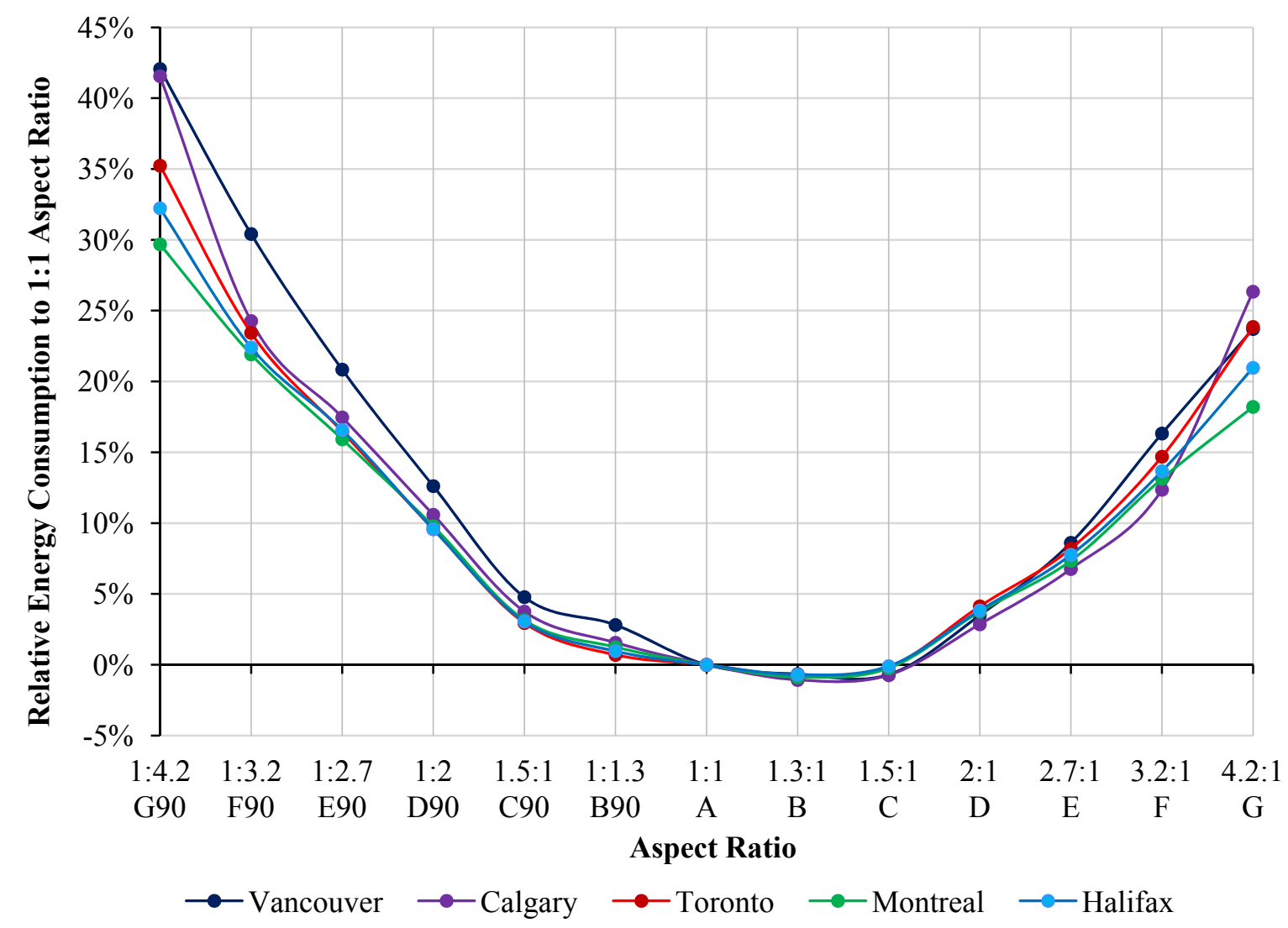

\subsection{Annual Energy Consumption Analysis: Cooling}

The cooling consumption is reduced moderately between an aspect ratio of $1: 1.5$ (Profile C) and 2.7:1 (Profile E). All buildings with aspect rations along the east-west axis performed better than Profile A. Aspect ratios increasing along the north-south axis experience a sharp incline in consumption. The REC was observed to increase over $25 \%$ in all Profile $\mathrm{D} 90^{\circ} \theta$ simulations (Figures 14 and 15).

- REC decreases as the aspect ratio is increased from 1:1 along the east-west axis. The optimal aspect ratio was determined to be $2.7: 1$ for Profile D. This aspect ratio yielded an REC of $-2.6 \%$ to $8 \%$ for different locations;

- The slope of the REC increases significantly towards the larger profiles and indicates increased heat transfer for buildings with larger aspect ratios. This is expected, considering the large increase of surface area for each aspect ratio increment. The significance of solar shading is thus apparent when comparing the buildings oriented perpendicularly. 
Figure 14. Annual cooling consumption for aspect ratios in Canadian cities.

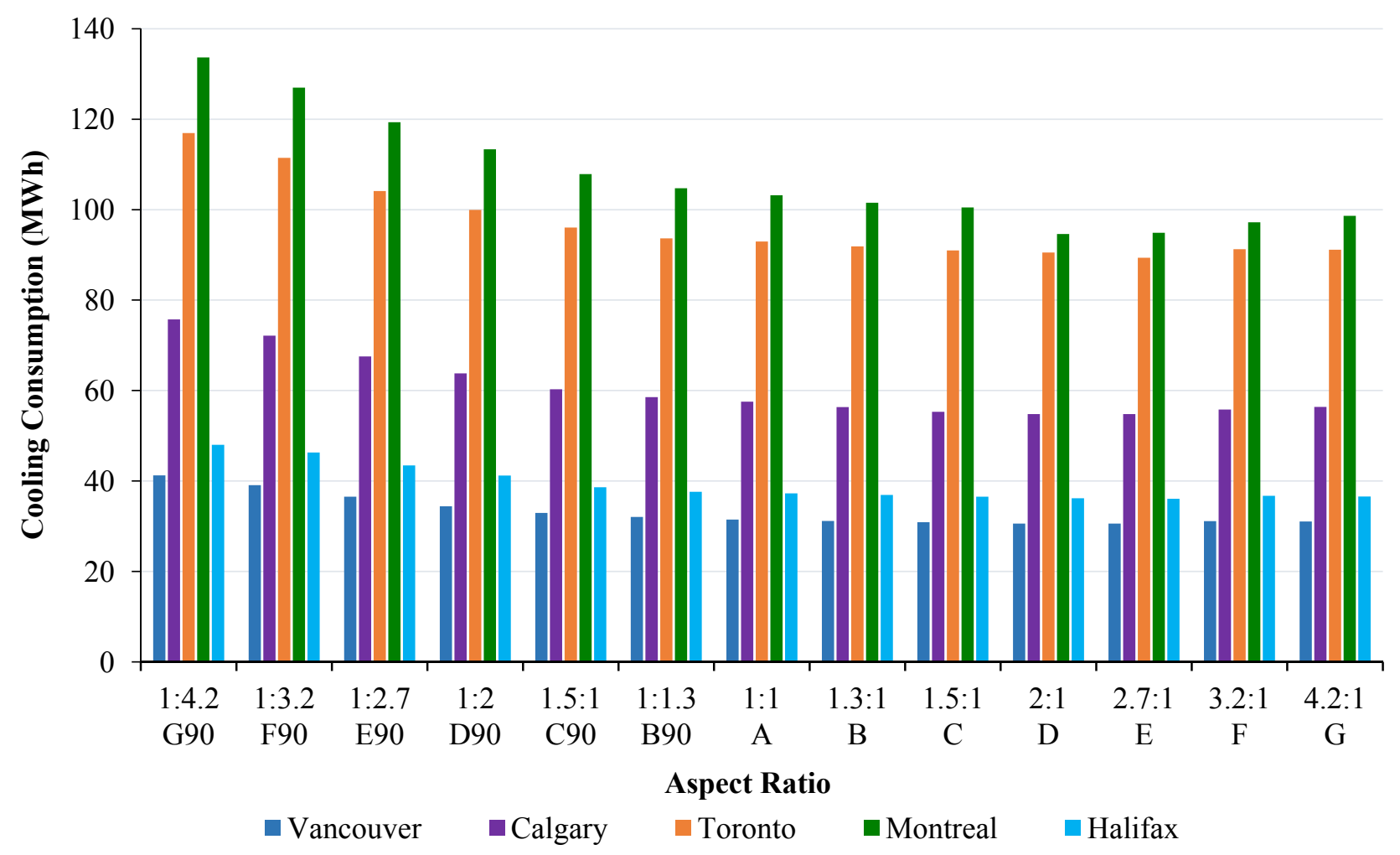

Figure 15. Relative energy consumption in cooling for aspect ratios.

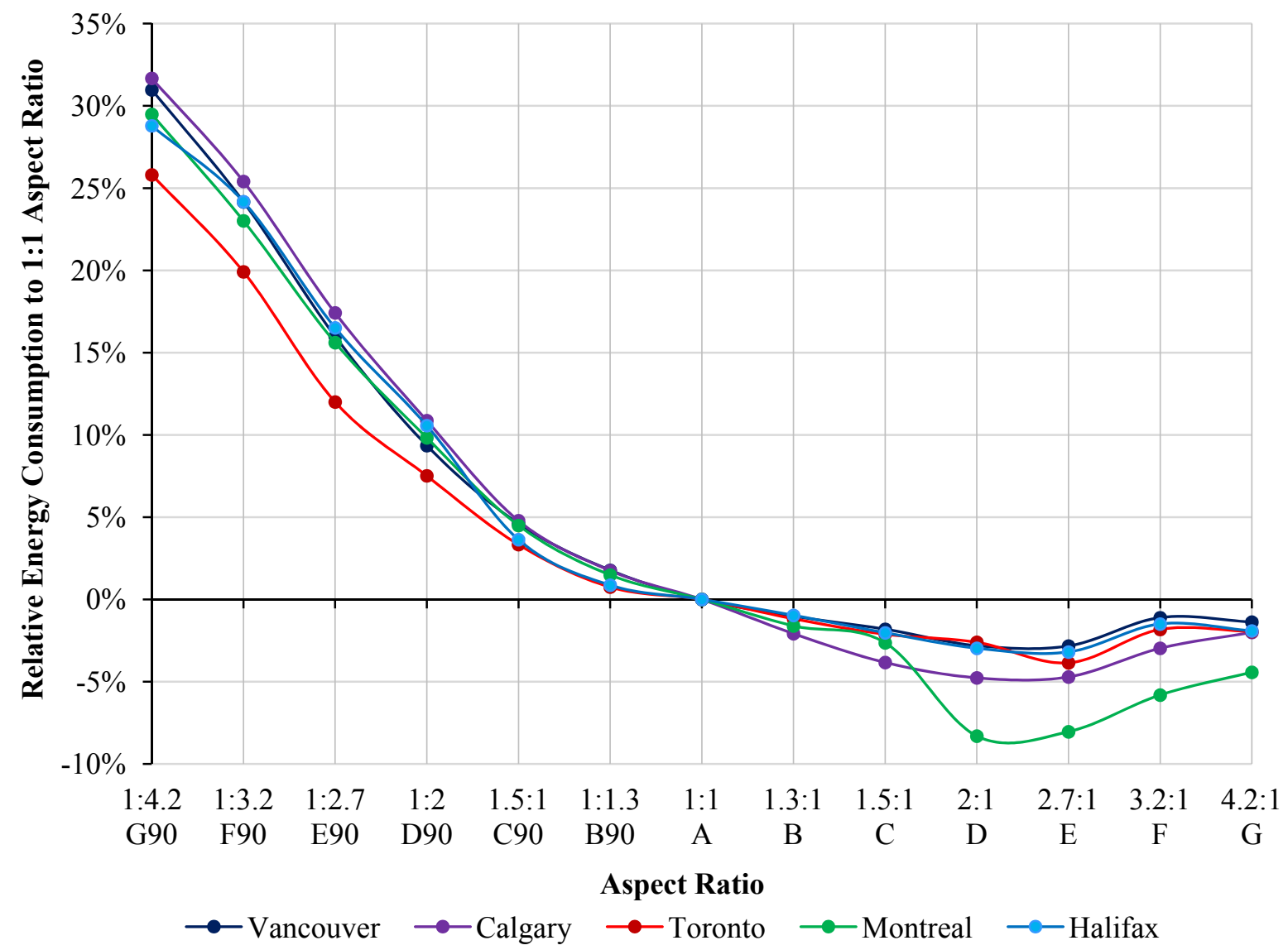




\subsection{Annual Energy Consumption Analysis: Combined Energy Consumption}

Heating and cooling are often provided by different fuel sources in Canada, depending largely on location. The most efficient aspect ratio is evidently one which utilizes the least total energy. However, because heating and cooling are often provided by different fuel sources, this makes the optimal aspect ratio different in terms of energy and economy. In regards to energy, the combined energy consumption (CEC) quantifies the total heating and cooling consumption. CEC is determined by the sum of cooling and heating energy consumption (Equation (4)).

$$
C E C=E_{\text {cool }}+E_{\text {heat }}
$$

The range of energy efficiency for a set of building aspect ratios can be defined by subtracting the maximum and minimum energy consumption (Equation (5)). This indicates the sensitivity of a specific location to a variations in its aspect ratios. A larger energy consumption range implies that a larger quantity of energy can be reduced through selecting an optimal design (Figure 16). Of the five cities, the largest range occurred in Calgary. With a maximum CEC of 3028 GJ in Profile D90 $\theta$ and a minimum CEC of 2418 GJ, the energy consumption range was over 600 GJ (Table 4). However, while the largest quantifiable energy savings could be achieved from the optimum aspect ratio in Calgary, proportionately, the largest savings could be seen in Vancouver (Equation (6)).

$$
\text { Energy Consumption Range }=C E C_{\max }-C E C_{\min }
$$

Proportional Energy Consumption Range $=\frac{\text { Energy Consumption Range }}{C_{E} C_{1: 1}} \%$

Figure 16. Combined energy consumption and energy intensity for aspect ratios.

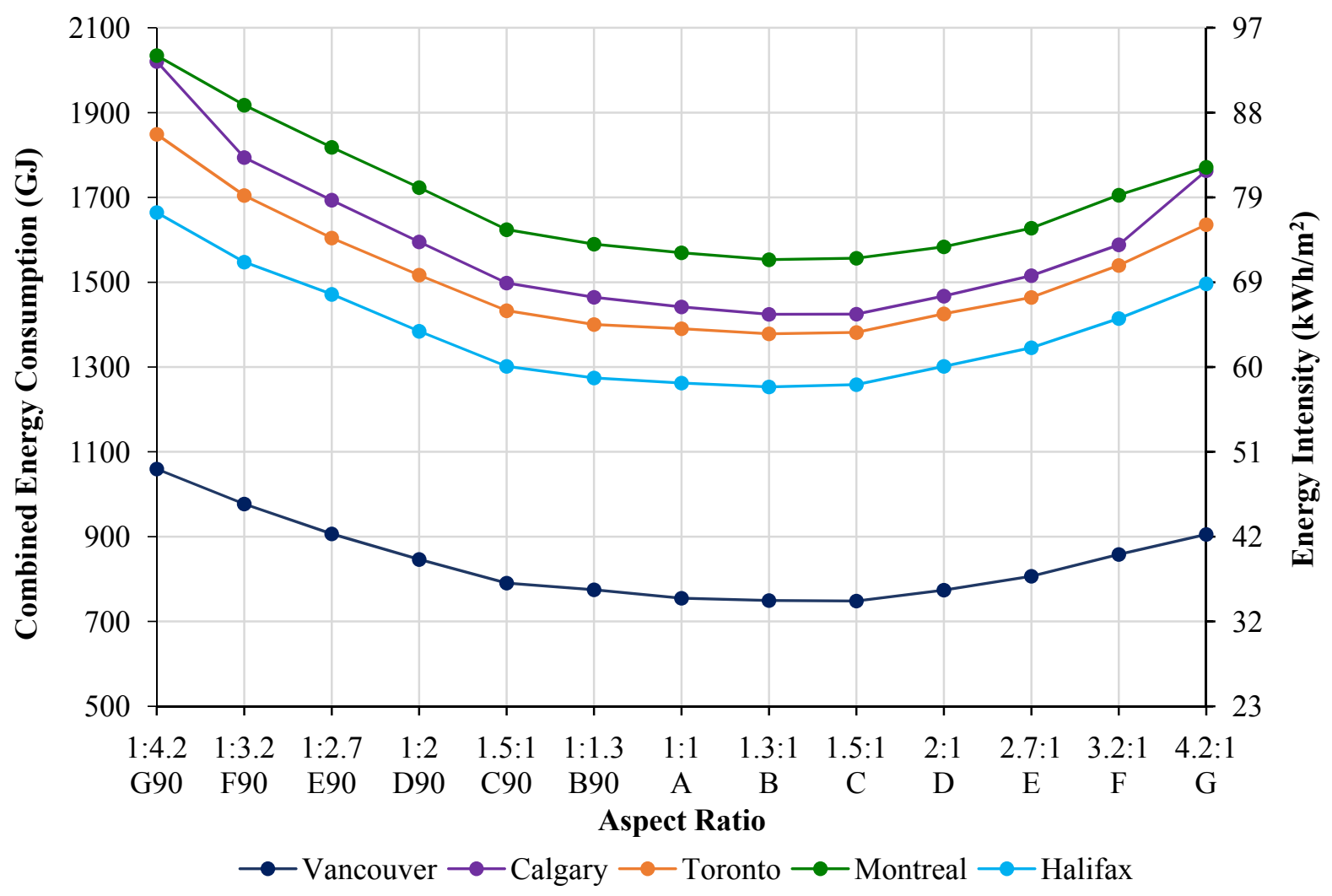


With a maximum CEC of $1060 \mathrm{GJ}$ in Vancouver Profile G90 $\theta$ and a minimum CEC of 755 GJ, the energy consumption range was only 311 GJ (Table 6). However, a reduction of 311 GJ is proportionately large. The proportional energy consumption range was $41.3 \%$ for Vancouver and $44.4 \%$ for Calgary. Halifax, in comparison, would yield only $32.6 \%$. Thus, this suggests that it may be easier to achieve a larger proportional reduction in cooling and heating consumption by utilizing optimal aspect ratios in Vancouver.

Energy intensity (EI) is determined by dividing the energy consumption of a specific aspect ratio by its floor area. This allows for a comparison of energy consumption between buildings of different sizes (Equation (7)).

$$
E I=\frac{C E C_{\text {aspect }}}{\text { Area }}
$$

Table 6. Energy consumption range and proportional energy consumption range.

\begin{tabular}{cccccc}
\hline Location & $\begin{array}{c}\text { Aspect Ratio } \\
\text { 1:1 (GJ) }\end{array}$ & $\begin{array}{c}\text { Most } \\
\text { Efficient (GJ) }\end{array}$ & $\begin{array}{c}\text { Least } \\
\text { Efficient (GJ) }\end{array}$ & $\begin{array}{c}\text { Energy Consumption } \\
\text { Range (GJ) }\end{array}$ & $\begin{array}{c}\text { Proportional Energy } \\
\text { Consumption Range }\end{array}$ \\
\hline Vancouver & 755 & 748 & 1060 & 311 & $41.3 \%$ \\
Calgary & 1442 & 1424 & 2021 & 596 & $41.4 \%$ \\
Toronto & 1391 & 1378 & 1849 & 471 & $33.8 \%$ \\
Montreal & 1569 & 1553 & 2035 & 482 & $30.7 \%$ \\
Halifax & 1262 & 1253 & 1665 & 411 & $32.6 \%$ \\
\hline
\end{tabular}

\section{Conclusions}

The predicted benefits of an optimal aspect ratio can result in significant heating and cooling savings. Simulated results are quantifiable and allow for quick referencing and ranking of performance. Understanding the degree to which the aspect ratio effects building performance is useful in building design. Compared to a building of a less efficient aspect ratio, such as 4.2:1, a reduction of energy consumption by over $15 \%$ is possible in many scenarios. Utilizing the optimal aspect ratio allows buildings to receive more solar gain in winter and shading in summer, decreasing the demand for heating and cooling. Additionally, the optimal aspect ratio has decreased peak loads, which can have a large impact on capital and operating cost. While many factors influence the building geometry, the importance of aspect ratio is considerable. The inclusion of optimal aspect ratios in design criteria will have a lasting impact on the future energy consumption of buildings.

\section{Author Contributions}

Philip McKeen is a Masters of Applied Science student in the Building Science program at Ryerson University. This study in building simulation was supervised by Alan Fung, a professor in the Mechanical and Industrial Engineering Department at Ryerson University. 


\section{Nomenclature}

\section{Notations}

$\begin{array}{lll}A & \text { Area } & \left(\mathrm{m}^{2}\right) \\ E & \text { Energy } & (\mathrm{MWh}, \mathrm{GJ}) \\ k & \text { Conductivity } & \left(\mathrm{W} / \mathrm{m}^{2}\right) \\ L & \text { Wall thickness } & (\mathrm{m}) \\ Q & \text { Quantity of heat } & (\mathrm{J}) \\ C & \text { Specific heat } & (\mathrm{J} / \mathrm{kg}-\mathrm{K}) \\ T & \text { Temperature } & (\mathrm{K}) \\ \frac{d V}{d t} & \text { Ventilation rate } & \left(\mathrm{m}^{3} / \mathrm{s}\right) \\ V & \text { Volume } & \left(\mathrm{m}^{3}\right)\end{array}$

Greek Symbols

$\theta \quad$ Rotation angle of building footprint

$\rho$ Density $\quad\left(\mathrm{kg} / \mathrm{m}^{3}\right)$

Abbreviations

CEC Combined energy consumption (GJ)

EI Energy intensity $\left(\mathrm{kWh} / \mathrm{m}^{2}\right)$

REC Relative energy consumption (\%)

\section{Conflicts of Interest}

The authors declare no conflict of interest.

\section{References}

1. Chiras, D. The Solar House: Passive Heating and Cooling; Chelsea Green Publishing: White River Junction, VT, USA, 2002; pp. 19-24.

2. Binkley, C.; Touchie, M.; Presnail, K. Energy consumption trends of multi-unit residential buildings in the city of Toronto. 2013; p. 12. Available online: http://www.towerwise.ca/ wp-content/uploads/2013/07/TAF-MURB-Energy-Performance-Report-Phase-II.pdf (accessed on 2 July 2014).

3. Natural Resources Canada (NRCan). Survey of Household Energy Use 2007-Detailed Statistical Report; NRCan, Office of Energy Efficiency: Ottawa, Canada, 2008; pp. 164-185.

4. Straube, J.; Burnett, E. Building Science for Building Enclosures; Building Science Press, Pennsylvania State University: State College, PA, USA, 2005; pp. 30-745.

5. RDH Building Engineering Limited. Energy Consumption and Conservation in Mid and High-Rise Residential Buildings in British Columbia, Canadian Mortgage and Housing Corporation Research Report 2012. Available online: http://www.hpo.bc.ca/sites/www.hpo.bc.ca/files/ download/Report/MURB-EnergyStudy-Report.pdf (accessed on 10 January 2014). 
6. Danielski, I.; Fröling, M.; Joelsson, A. The Impact of the Shape Factor on Final Energy Demand in Residential Buildings in Nordic Climates. Mid Sweden University: Östersund, Sweden, 2012. Available online: http://www.diva-portal.org/smash/get/diva2:532979/FULLTEXT01.pdf (accessed on 10 January 2014).

7. Fennell, H.; Haehnel, J. Setting Air Tightness Standards. ASHRAE J. 2005, 47, 26-31. Available online: http://www.ashrae.org/File\%20Library/docLib/Public/200583084452_886.pdf (accessed on 22 January 2014).

8. Hachem, C.; Athienitis, A.; Fazio, P. Parametric investigation of geometric form effects on solar potential of housing units. Sol. Energy 2011, 85, 1864-1877.

9. Hirsch, J.J. eQUEST: The QUick Energy Simulation Tool, Version 3.65. Available online: http://www.doe2.com/eQuest/ (accessed on 20 March 2014).

10. Canadian Home Builders' Association (CHBA). The CHBA Poll, 2012. Available online: http://www.chba.ca/uploads/pulse\%20survey\%20results/main\%20report2012.pdf (accessed on 22 January 2014).

11. American Society of Heating, Refrigerating and Air Conditioning Engineers (ASHRAE). ASHRAE Standard 90.1-2007 Energy Standard for Buildings Except Low-Rise Residential Buildings; ASHRAE: Atlanta, GA, USA, 2007.

12. Hill, D. Ventilation Systems for Multi-Unit Residential Buildings: Performance Requirements and Alternative Approaches; Technical Series 03-121; Research Highlights Canadian Mortgage and Housing Corporation: Ottawa, Canada, 2003; Volume 2. Available online: http://www.cmhcschl.gc.ca/odpub/pdf/63280.pdf (accessed on 24 May 2014).

13. RDH Building Engineering Limited. Air Leakage Control in Multi-Unit Residential Buildings, Canadian Mortgage and Housing Corporation Research Report. Available online: http://rdh.com/ wp-content/uploads/2014/04/Air-Leakage-Control-in-Multi-Unit-Residential-Buildings.pdf (accessed on 10 January 2014).

14. American Society of Heating, Refrigerating and Air Conditioning Engineers (ASHRAE). ASHRAE Handbook - Fundamentals; ASHRAE: Atlanta, GA, USA, 2009.

15. Environment Canada, Canadian Climate Normals 1971-2000. Vancouver Toronto, National Climate Data and Information Archive, 2013. Available online: http://climate.weather.gc.ca/ climateData/ (accessed on 10 January 2014).

16. Hutcheon, N.; Handegord, G. Building Science for a Cold Climate; National Research Council of Canada: Toronto, Canada, 1983; p. 407.

17. Townsend, A.; Ueno, K. Effects of Air Conditioner Sizing on Energy Consumption and Peak Demand in a Hot-Dry Climate; 2008 ACEEE Summer Study on Energy Efficiency in Building; American Council for an Energy Efficient Economy: Washington, DC, USA, 2008; pp. 1-291.

(C) 2014 by the authors; licensee MDPI, Basel, Switzerland. This article is an open access article distributed under the terms and conditions of the Creative Commons Attribution license (http://creativecommons.org/licenses/by/3.0/). 